\title{
The Variations of the Teacher Profile as Reflected in the Curricula of Teacher Training in Cyprus
}

\author{
Lefkios Neophytou \\ School of Education, University of Nicosia

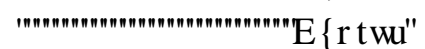 \\ प
}

\begin{abstract}
:
This paper will review the various curricula underpinning teacher education for elementary school teachers in Cyprus and describe the variations of the indented teacher profile from the English colonial period to the present day. We will discuss how and why the intended teacher profile has shifted from a clear, concise and consistent ethnocentric perspective to a more vague and ambiguous approach that resulted from the allocation of the responsibility for teacher training, from the state to the university. This paper concludes by proposing a new framework that can be used to describe the intended teacher profile in contemporary times taking into consideration the open systems perspective and the notion of autonomy at universities.
\end{abstract}

Key words: Curriculum traditions; comparative historical analysis; social systems; University.

Corresponding author: Lefkios Neophytou

E-mail: lefkios@ucy.ac.cy

Educational Research eJournal - ISSN 2254-0385

(C) Faculty of Education. University of Alicante

DOI: $10.5838 /$ erej.2012.11.03 


\section{Introduction: Curriculum theory and teacher training}

What teachers do we want to have? What should teachers know? How should teachers teach? What should be the impact of teachers on students and society?

These fundamental questions have guided teacher education throughout time. However, the answers to these questions have been differentiated in various historical periods focusing on different perspectives and stressing several, and often competing, emphases about curriculum and the role of education. Scholars (i.e. Eisner \&Vallance, 1974; Kliebard, 1986; Zeichner \& Liston, 1990; Vallance, 1986) have tried to capture the essence of these variations through the development of different theoretical frameworks, often called traditions or models. These reflect the various attempts undertaken to map the educational field and to provide an answer to the question of relevance: What is the most important thing that education should pursue? Despite their differences, all the theoretical frameworks converge upon four major pillars reflecting, more or less, the mapping proposed by Herbert Kliebart (1986) in his seminal historical study: the humanistic tradition, the social efficiency, the developmental (or cognitive/child study) and the social meliorist (or social reconstruction) tradition.

In terms of the humanistic tradition, the most important thing that education should pursue is the preservation and safekeeping of an ancient tradition tied to the power of reason and the finest elements of the Western cultural heritage (Kliebart, 1986). The notion of «academic rationalism» (Eisner \& Vallance, 1974) is embedded in the humanistic tradition. Academic rationalism is based on the assumption that ideas within the various disciplines have a distinct nature and structure. Hence curricula and education should be focused on passing on to the next generations both the knowledge but also the structures associated with each different discipline. Knowledge becomes the condition for preserving knowledge and the teacher is the custodian of tradition.

On the other hand, the developmental approach is tied to the natural order of development in the child and holds that this is the most significant and scientifically defensible basis to determine what should be taught. To this extent, the developmentalists favour a curriculum that is based on solid evidence about both the nature of learning and the different stages of the intellectual development of the human mind (Kliebart, 1986). Hence, the teacher becomes a cognitive engineer and the curriculum seeks to develop to the learner a repertoire of cognitive skills applicable to a wide range of problems (Eisner \& Vallance, 1974).

The Social Effectiveness tradition stresses on the importance of scientific inquiry in determining the needs of the society and the activities needed to fulfill these needs. It considers that the role of education is to find these needs and prepare individuals for life in the future through the development of the necessary competencies and skills. Consequently, curriculum is aligned with the application of the «standardised techniques of industry to the business of schooling» (Kliebart, 1986, p.28) while the teacher becomes an efficient manager.

Finally, the Social Meliorism (or social reconstruction) tradition (Kliebard, 1986) is focused on social injustice and attempts a reconceptualisation of education by 
considering the school as the primary force for social change and justice. Curriculum is henceforth put in the service of social improvement or, at its most radical end, in the service of social reconstruction. Doubt and deconstruction of dominant and unchallenged norms become principle notions of education that is committed to emancipation and the creation of a better society. In this framework, the teacher is considered to be an intellectual and an agent of political transformation.

Teacher education in different periods of history has been aligned with these four traditions. Based on the answer given to the question "What counts the most in education" a specific profile for the teacher has been developed. This profile was focused on how societies can, in the most effective manner, fulfil their aspirations. In this direction, teacher education curricula, echoing the trends in educational theory and research, focuses on the traits, skills and even the character of the perspective educators.

As we attempt to explain the development of teacher education in Cyprus we must of course keep in mind these traditions. Nevertheless, the effect that these traditions have had on teacher education is neither analogous nor synchronous to the effect that these have had on other countries. Moreover, we need to consider the fact that none of these traditions have been used on their own to define an educational policy, even in the countries in which these traditions emerged. As Kliebart (1986, p.29) concludes in his study «in the end, what become the ... curriculum ${ }^{1}$ was not the result of any decisive victory by

\footnotetext{
${ }^{1}$ Kliebart refers to the American curriculum. However his conclusion can be applied in other contexts as well.
}

any of the contending parties, but a loose, largely unarticulated and not very tidy compromise».

Should we discard these traditions when attempting to illuminate the changing landscape of education and teacher training in Cyprus? The argument underpinning our current discourse is based on the assumption that the options in the curriculum in countries with longstanding political problem, such as Cyprus, require new theoretical frameworks of interpretation since the prevailing theories are not sufficient to interpret and justify the dominant ethnic and consequent educational culture that seals each option. Yet, any particular social, political or economic conditions that affect education will remain redundant if not inducted into an overlying theoretical framework that will enable to compare, contrast and explain the variations among different educational systems in the historical continuum. With this purpose, the conceptual models portraying curricular theory will be used as interpretative tools through which we will attempt to explain the diversification of teacher education in Cyprus, taking into account the specific conditions and circumstances of the local context.

\section{Methods}

The purpose of this study was to investigate the various educational/ curricular models applied in different historical phases in the training of elementary school teachers in Cyprus. The method of Comparative Historical analysis (CHA) was employed in this study. CHA examines historical events in order to provide explanations that are valid beyond a particular time and place, either by direct comparison to other historical events, theory building, or 
reference to the present day (Mahoney \& Rueshemeyer, 2003; Mallinson, 1980). Schutt (2006) proposes four steps in CHA: (1) develop the premise of the investigation via identifying any events or concepts that may explain the phenomena; (2) choose the cases to examine; (3) examine the similarities and the differences; and (4) propose a casual explanation for the phenomena based on the information gathered.

In our study, we gathered data about the training of elementary teachers in Cyprus starting from the British colonial period to the modern day. Data were collected mostly through secondary resources. However, certain data were collected using primary resources (e.g The Yearbooks of the Pedagogical Academy of Cyprus, the Undergraduate Prospectus of the University of Cyprus). The framework of curricular traditions (proposed by Kliebart, 1986) was used to examine the similarities and differences between the various models of teacher training in different historical phases, while the objective circumstances pertaining different eras (in terms of ideology, politics and social structures) informed our analysis concerning the provision of a causal explanation about the variations that occurred in teacher training.

\section{Unravelling the skein of teacher education in Cyprus during the British colonial period and the early period of independence}

The humanistic tradition as a result of unfulfilled national goals, its collision with the social effectiveness tradition and its interplay with the social reconstruction tradition.

In our attempt to understand the way teachers were trained in Cyprus we need to familiarise the reader with the changing educational landscape and its variations in different historical times. Hence, we begin with a brief description of the history of teacher training in Cyprus. Our discussion will be focused on the education of the Greek elementary-school teachers in Cyprus. Despite the interest that the education of Turkish Cypriot teachers may have, it is not within the scope of this paper to describe it, bearing in mind that the education systems and teacher training in Cyprus were, for most of the time, separate for the two communities.

The first teacher training institution (for elementary school teachers) to be established in Cyprus was the PanCyprian Teacher Training School in 1893, when Cyprus was under the British rule. Throughout the British colonial period (1878-1960), the Greek Orthodox Church established itself as the centre of religious, educational, and cultural activities aiming at the establishment of schools that were able to strengthen the Greek tradition and culture (Pasiardes, 2007; Persianis, 1978; 1992). In this framework, teachers were considered primarily as national workers and their education relied on the knowledge of Greek language and history and the Christian Orthodox religion (Kokkinoftas, 1997). Evidently, the underlying assumptions of teacher education in Cyprus at the time were in line with the humanistic tradition. This reflected an ongoing struggle of the Greeks in Cyprus to preserve their national identity. Teachers were considered as the prime "guardians" of the ancient Hellenic tradition and teacher education was considered as the process by which the selected and socially cherished content (Greek history, language and religion) was transmitted. Due to the minimal interference of the colonial 
government in the education of the Cypriots, the humanistic tradition flourished throughout the first 50 years of the British administration (18781929).

However, this situation changed when the British governor abolished all the teacher-training institutions and established in 1937 the Morphou Teacher Training College offering two-year training in English both for Greek and Turk male teachers. A few years later (in 1943) a female teachers ${ }^{\text {ee }}$ college was founded in Nicosia. These two colleges were unified in 1958 and a bi-communal/ bi-gender college was founded in Nicosia (Maratheftis, 1992). In the light of the various advancements of the pedagogical science and the uprising of the progressive school movement that flourished at the time in England, the colonial government justified the changes in teacher education using the argumentation of modernisation (Koutselini, 1997). Hence, the removal of the educational control from the church and its allocation to the government was justified in terms of the social effectiveness and developmental tradition that needed an up-to-date model for teacher education to meet the needs of the society and the learner. In this rhetoric, the learner was no longer considered as a carrier of a national identity, but as an individual with distinct needs and abilities at different phases of his/her intellectual development. Nevertheless, despite the control that the British government established on education, the dominant ideology and the envisaged teachers ${ }^{\text {ee }}$ role remained the same. The colonial educational policy collided with the aspirations of the Greek Cypriots who were suspicious of any modernizing attempts (Weir, 1952). Humanism was still considered the cherished educational ideology, reflecting the national goal of ENOSIS: the unification of Cyprus with Greece (Persianis, 1981; Polyviou, 1980).

Observing the context of Cypriot education at the time, we observe an oxymoron: A peculiar and controversial alliance between the humanistic and the social reconstruction tradition. The oxymoron here is that the former tradition is based on preservation and the latter on change. However, in the specific historical context, the humanistic tradition is reinvented and reinforced, thus becoming the vehicle of change. A change that would, however, enhance the return of the tradition. Despite the peculiarity that this interplay of traditions may have, it can easily be explained using the perspective of the postcolonial theory (Fanon, 1961; Ngugi, 1981; Neophytou, 2004). Colonial oppressive regimes attempt to disconnect people from their historical roots. Hence, the oppressed need to revisit their past-the era before the colonial period- and understand that their current lives are not "determined" by their nature but "conditioned" (Freire, 1998) by the colonists. Hence, tradition becomes the tool for change that would result into the restoration of the national pride.

This trend continued, even when Cyprus became an independent republic in 1960. Reflecting the unfulfilled desire for ENOSIS among the Greeks of Cyprus the independent state was considered as something imposed by foreign powers. The republic of Cyprus was regarded as a deviation from the national goal and therefore treated as temporary solution- an intermediate phase in the process of fulfilling the goal of ENOSIS (Kizilgiourek, 1999; Papadakis, 2005). Thus, as soon as Cyprus became an independent state, the prime goal was to reestablish teacher education to its 
classical Hellenic roots. The Teacher Training College established by the British in Nicosia, was renamed in 1959 as the Pedagogical Academy of Cyprus $(\mathrm{PAC})^{2}$. The curriculum of the PAC was "Hellenized" (decision of the Greek Communityes Educational Board" during its meeting on 28 May $1959^{3}$ ) and modelled on the Greek prototype, following the curricula of the pedagogical academies in Greece (Persianis, 1981). Furthermore, the teaching of the English language was abolished and its teaching hours were allocated to lessons to strengthen the Greek language. The PAC curriculum emphasised lessons that were considered important in terms of connecting students with their tradition (i.e. Ancient Greek, Greek literature, History of the Greek civilization, Popular Greek culture) (Maratheftis \& Koutselini, 2000). Consequently, PAC, as the highest educational institution in Cyprus echoed the zeitgeist of the Greek Cypriot society at the time and assumed a predominantly national role.

However, in 1967 teacher training in Cyprus progressively began to deviate from the Greek model. The first president the Republic of Cyprus, Archbishop Makarios III, declared the policy of the "attainable"(what we can achieve) rather than the "desired" (what we wish) signifying the formal abandonment of ENOSIS as the prevailing national goal. Consequently, certain lessons introduced in 1967 by the military regime in Greece (i.e. Popular education) were never included in the curriculum of the PAC. Furthermore, the PAC continued to offer a three-year cycle of studies despite the fact that teacher training

\footnotetext{
${ }^{2}$ In fact the Teacher Training College was turned over to the Greek community of Cyprus even before the independence in 1959, hence preparing for independence from Britain in 1960 (Maratheftis, 1992).

${ }^{3}$ PAC Yearbook (1959-1960)
}

in Greece was reduced to two years (Maratheftis \& Koutselini 2000). Within the process of disengagement from the Greek model, the faculty of the PAC declared in 1970 that the aspired teacher education should be equally determined by national, educational, cognitive and sociological goals along with goals for personal development (PAC Yearbook 1969-1970). By 1972 the Greek-centred courses (Greek literature, History of Greek Culture, Ancient Greek) were gradually reduced in terms of instructional hours and finally abolished while several other courses (such as Philosophy, Psychology, Sociology, General Instruction, Music, Physical Education and Art) were significantly upgraded in terms of content and duration (PAC Yearbook 1971-1972).

Yet, the most significant shift in teacher education occurred after the Turkish invasion in 1974. Feelings of betrayal and abandonment ("mother Greece abandoning its child") (Mavratsas, 1997; Papadakis, 2005) leveraged a further detachment from the Greek curricula. Hence in the 1976 reform, new courses were introduced particularly in the cycle of Pedagogical-Psychological studies (i.e. Psychology of adaptation, Social Psychology, Developmental Psychology, Psychology of Learning, Psychopathology and Treatment of Divergent Children, Educational Research and Statistics). Moreover, certain courses were renamed (e.g. Religious Education to Psychology and Sociology of Religion) signifying a differentiation in terms of their purpose and content (Maratheftis \& Koutselini, 2000). The aspired model of the teacher as a national worker gave way to the teacher as "a technocrat, able to teach all subjects in all grades of primary school or kindergarten, and simultaneously able to evolve as a free 
and responsible person who can think critically and is able to cooperate with others for the common good" (Maratheftis, 1984, PAC yearbook, 1979, p.160). Notions, formerly considered as taboo, such as the "Greek Cypriot Youth", the "Cypriot society" and loyalty to the "Republic of Cyprus" "were "taken out of the closet" and appeared in the studentse "Oath of Graduation". As a consequence, within the changing landscape of education in Cyprus, the humanistic tradition, so stubbornly preserved throughout the colonial years, gave way to an amalgam of traditions consisting mostly of assumptions and ideals of both the social effectiveness and the developmental tradition. Abandoning the quest for ENOSIS, teacher education was oriented to find optimum ways to transform teachers into technocrats, able to understand the nature of human intelligence and development and use their knowledge to effectively teach their students. This trend was sustained until 1993 when the PAC was closed. Henceforth, the PAC was succeeded by the University of Cyprus (UCY), which undertook the task of teacher training in Cyprus.

\section{The contemporary context of teacher education in Cyprus}

Segments of traditions in an ideological aspiration

Even though many options are now available for Cypriots pursuing a career in teaching ${ }^{5}$, the Department of Education at

\footnotetext{
${ }^{4}$ These notions were considered taboo since they were connected to the development of a Cypriot identity, an identity that collided with the notion of ENOSIS. In the context of ENOSIS, the aspiration was to sustain the GreekHellenic identity that would enhance the fighting spirit towards the fulfillment of the goal of unification. ${ }^{5}$ Today, the initial training for elementary education teachers in Cyprus, is conducted by one public (the University of Cyprus) and three private universities (University of Nicosia, European University Cyprus and Frederick University).
}

the University of Cyprus (UCY) can still be considered as the main successor of the PAC tradition. A tradition directly conveyed to the UCY in 1993 when the PAC was closed (since it was the only university in Cyprus at the time) and moreover, being at the present time the only public higher education institute offering initial teacher training for elementary school teachers. To this extend, our analysis will focus on the Department of Education of the UCY.

Which is the profile that the department of education pursues for its graduates? An initial answer to this question may be provided by skimming through the program of studies as published in the Undergraduate Prospectus of the UCY (2010-11). As stated in the prospectus (p.147), "the mission of the Department of Education is to meet the national, cultural and developmental needs of the island".

Specifically, the mission of the Department is as follows:

-Producing and disseminating knowledge in the Pedagogical Sciences.

-Identifying, researching and studying educational issues.

-Educating Elementary and Kindergarten Teachers for Cyprus schools.

-Providing pedagogical training for those wishing to teach in Secondary and Technical Education.

-Providing in-service training and staff development courses for school personnel.

-Providing graduate programs with the aim of preparing research personnel and people who will assume leadership positions within the educational system.

As declared, the program is designed to meet the needs of the Cypriot society. Hence, even though the intended teacher profile is not clearly articulated, we may infer that the teacher profile 
will be determined by the results of socioeconomic research and the application of the «standardised techniques of industry to the business of schooling》 (Kliebart, 1986, p.28). In this sense, the aspired teacher is the teacher /manager, trained to train his/her students to meet certain socioeconomic benchmarks and indicators. Hence, the rationale that underpins teacher training at the UCY appears to be aligned (mostly) with the social effectiveness tradition. Or is it not? A more detailed observation may lead us to different conclusions.

Despite the fact that the department defines its mission as the fulfilment of the needs of the island, this statement is downgraded by the elaboration that follows. Observing the specific objectives that outline the general aim, we can distinguish that the prime goal of the department is the production and dissemination of knowledge. In this sense, it is not the social effectiveness tradition that directs teacher training but the academic rationalism embedded in the humanistic tradition. Preserving the structures of knowledge and tuning graduates and societies to consume and apply the knowledge produced by the universities. Still, social effectiveness is not discarded. It becomes however, a by-product of the main processes of research, production and dissemination of knowledge. Therefore it is still important to train teachers to meet the needs of the island, but, this is done so that the department can persuade the society about its necessity and, consequently, continue to attract resources to preserve itself!

The intended teacher profile, despite not being clearly articulated in the mission statement of the Department of Education at the UCY, appears to reflect notions and assumptions of the both the academic and the social effectiveness tradition. Still, conclusions made at this point are premature. Therefore, we continue our quest to establish an understanding about the intended teacher profile by examining the program of studies for teacher candidates (Graph 1 \&Table 1- appendix).

Graph 1: Areas of studies in the program for elementary school teachers at the University of Cyprus (Undergraduate prospectus, 2010-11).

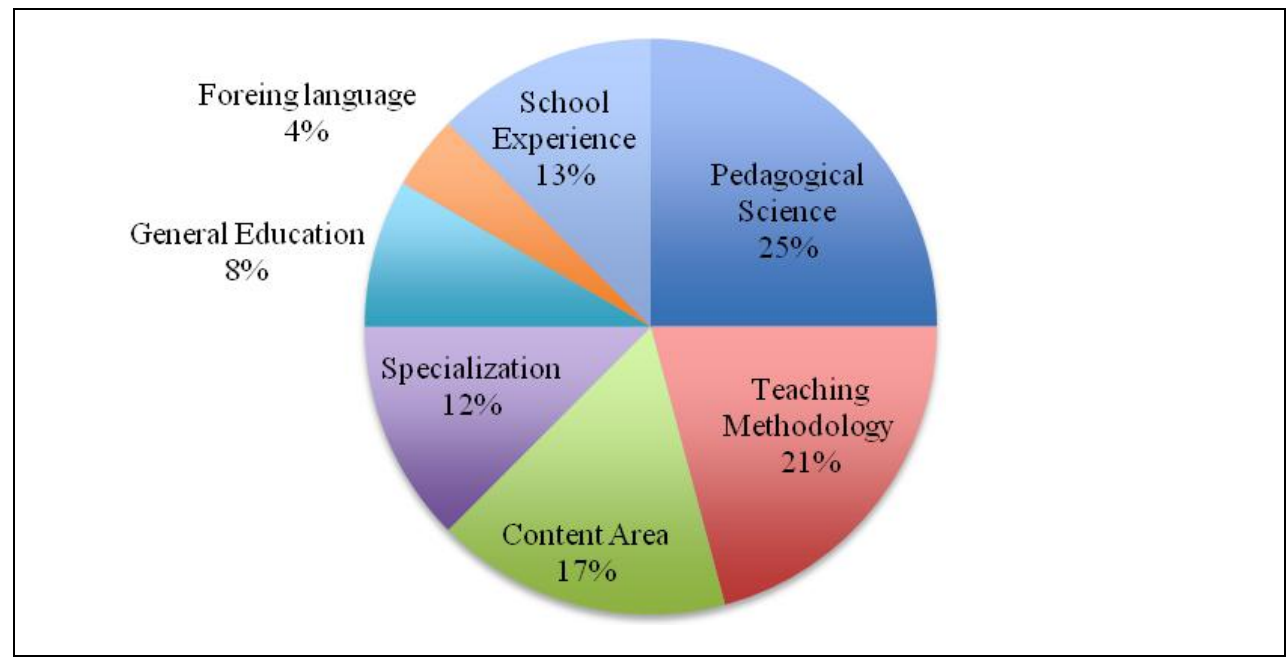




\section{Table 1: Program of Study for elementary school teachers (University of Cyprus- Undergraduate prospectus 2010-11, p.158).}

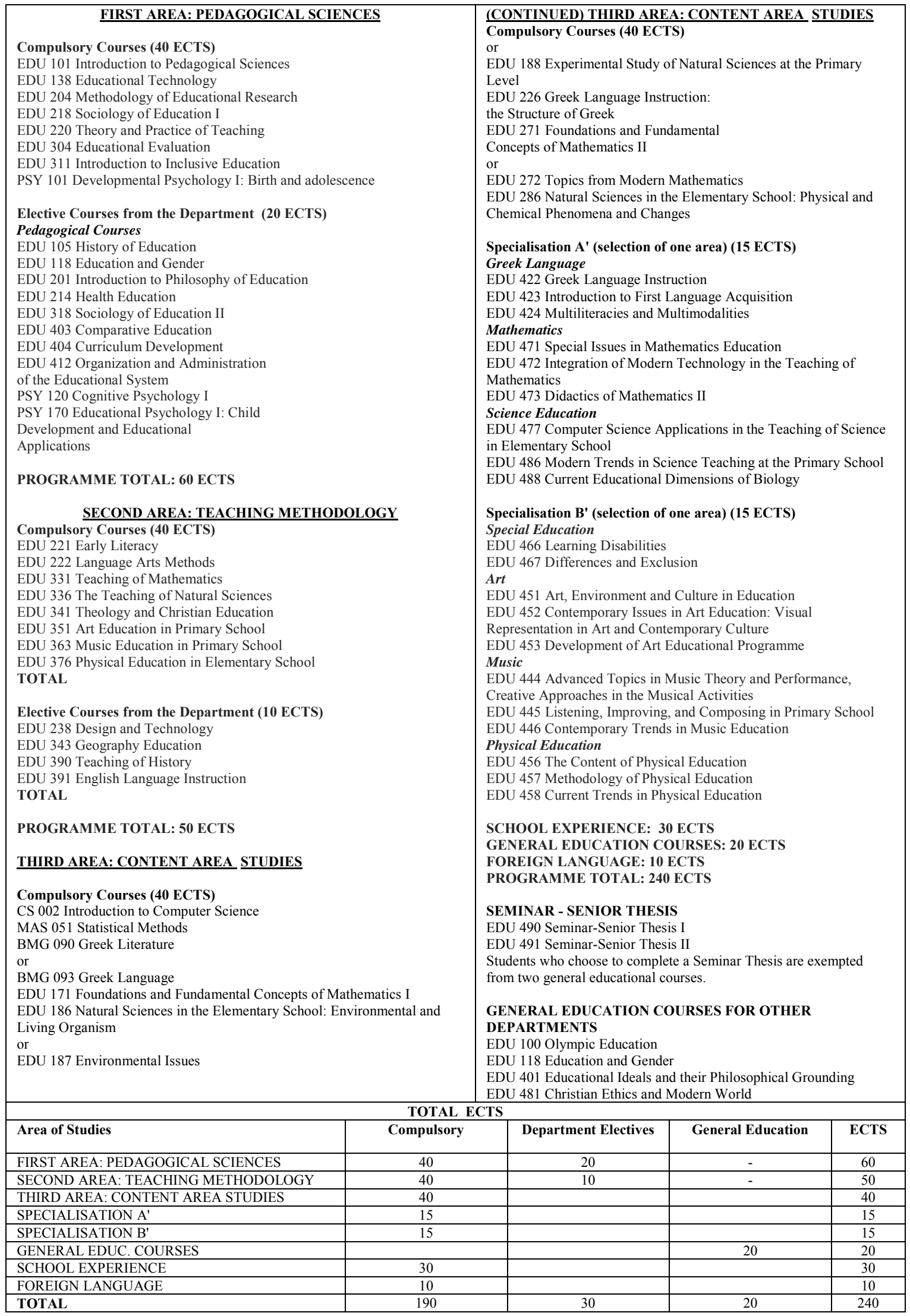


Graph 1 illustrates the types of lessons offered in the program for elementary school teachers. Most of the courses $(59 \%)$ have to do with generic skills and knowledge in pedagogy and instruction (25\% Pedagogical Science, 21\% Teaching Methodology, School Experience13\%). To this extent, the apparent focus of the program is on the provision of a broad set of abilities that would empower the teacher to teach any topic in his/her classroom. Content area lessons $(17 \%)$ are supportive of the program 's emphasis since they provide additional knowledge and skills in certain topics that are considered to be the most important for prospective educators (e.g. Mathematics, Greek Language, Natural Sciences-see Table 1). Hence, observing the program at its core $(76 \%$ of the courses) we can conclude that it is directed to the development of multiknowledgeable, multi-skilled and multidimensional teacher.

The remaining $24 \%$ of the courses may be considered supplementary to the main focus of the program. This percentage is indicative of the intention of the department to provide a broader perspective to its students ( $8 \%$ General Education, 4\% Foreign Language), an intention that however remains ill supported: Are 4 courses enough to provide general knowledge to a student? In terms of the foreign language, no one actually expects that a student, without any prior knowledge in a foreign language will be become able to effectively use and understand that language through two courses. The same applies for the Specialisation Courses (12\%): How can a student become an expert in certain disciplines through 3 courses. One may argue that specialisation areas build on previous courses offered in the program. This may apply to the areas of Mathematics, Greek and Natural Sciences since many other courses are offered as compulsory or elective. It definitely does not apply in the specialisations of Art, Music, Physical Education and Special Education.

Shifting, once again, our discussion to the underlying traditions, we can argue that the program is influenced by the social effectiveness and the developmental tradition. The social effectiveness tradition is reflected by the emphasis placed on certain lessons of a "positivistic" nature (e.g. Mathematics and Physical Education) that are considered important for contemporary societies (European Communities, 2001; OECD, 2007). This trend is also reflected by the provision of courses in foreign language learning. On the other hand, the developmental tradition, appears to be even more influential than the social effectiveness tradition since it resides at the core of the notion of pedagogy and effective teaching methods which are infused in most of the courses offered by the department.

What about the humanistic tradition? Is it totally excluded from the program? As earlier noted, the notion of Academic rationalism embedded in the humanistic tradition is based on the assumption that ideas within the various disciplines have a distinct nature and structure. Hence, the fact that the courses are named through discrete disciplinal descriptors (mathematics, natural science etc.) indicates that the academic tradition is still in use. However, it is apparent that teachers are not considered as the guardian of the ancient Hellenic tradition. Again, observing table 1, we notice that the program does not include any 
"Hellenizing" courses (e.g. Ancient Greek, Greek history, Greek civilization) as the early programs of the PAC. Courses using the word Greek in their title aim to empower prospective educators to teach the Greek language effectively (e.g. EDU 226, 442) and not to produce "national workers". The same applies for history courses whereas only one elective course is offered (EDU 390). This course is focused on instruction rather than content and knowledge of the Greek history. Nevertheless, segments of the "national workers" tradition are preserved through the provision of certain courses in religious education: the program includes a compulsory lesson on Religious Education (EDU 341 Theology and Christian Education) and one elective (EDU 481 Christian Ethics and the Modern world). Is this an inconsistency? Again, revisiting Kliebart's words (1986) we can see that in the end, the curriculum is not the result of any decisive victory by any of the contending parties, but a loose, largely unarticulated and not very tidy compromise.

Concluding our discussion so far, we have seen that the intended teacher profile of the department of education at the UCY appears to be the outcome of an accumulation of segmented notions and assumptions. The program seems to be mostly influenced by the Social Effectiveness and the Developmental tradition. The Humanistic tradition, even though is treated as an impoverished partner, still endures and claims its part in the creation of the intended teacher profile. Considering however, that the selection of content, methods and bibliography is a non-negotiable prerogative of every faculty member, any conclusion about the type of teacher that the program seeks to produce will be arbitrary. As soon as a person becomes a faculty member, he/she may teach the lesson however he/she decides. The curriculum/program may provide a framework. This framework however, may take different forms and focus on different or even competing paradigms and assumptions. The instructor becomes the curriculum. Bearing in mind that freedom and autonomy in teaching are the founding stones of a university, we can argue that the intended teacher profile is no longer a conception that can be defined in terms of social agents and stakeholders. It becomes an internal affair of the university. Teacher training is no longer conducted in an after-chamber of the high school. Despite the fact that schools are designed to meet the needs and fulfil the aspirations of the society, universities are not bound by such conditions. Hence, universitiesand particular instructors- may or may not choose this mission. The use of generic models to describe teacher training can be applied, as long as government-controlled institutions conduct teacher education. However, these configurations are insufficient when teacher training becomes the responsibility of the university.

\section{Establishing a framework to describe the intended teacher profile in contemporary times - Open systems and the notion of autonomy in universities}

Universities are open systems because they need their environment to take inputs (e.g. labour, students and money) and subject these inputs to an educational transformation process that produces literate and educated student and graduates (Hoy \& Miskell, 2007). 
Therefore, universities need to persuade their environment in order to attract resources and continue to operate. However, the dependence on environmental factors gradually weakens as universities accumulate rights and privileges that accompany the notion of the academic and administrative autonomy. Since resources are generously and -in some cases- unconditionally gratified from the environment, and the continuance of the organisation is guaranteed $^{67}$, the university can backslide into becoming a closed system. As Karlsson (2011) asserts, people cannot only open closed systems; they can also close open systems. Hence, inner politics take over establishing a unique institutional culture that is resistant to environmental pressures.

Nevertheless, universities are not immune to their environment. Their functions and processes are largely influenced by the politics and agendas of major stakeholders (Hill, 2006; Rhoads \& Torres, 2006). However, the actual processes of teaching and learning, which constitute the "operational curriculum" (Goodlad, 1979), remain in the hands of every faculty member. In this sense, the framework to examine the intended graduate profile of a university department can be found by examining that particular department through the social systems perspective (Getzels \& Guba, 1957).

A social system is an open system. It is an organised whole comprising interacting personalities, bound together in an organisational relationship (Waller, 1932). It is characterized by an

\footnotetext{
${ }^{6}$ Two hundred people share two millions euro per year. Hefty allowances given to universities. (2011, December 1). Politis Newspaper, p.1.

${ }^{7}$ A bundle of millions to the university. (2011, December

8). Phileleptheros Newspaper, p.1.
}

interdependence of parts, a clearly defined population, differentiation from its environment, a complex network of social relationships and its own unique culture. All these determine who teaches, what and how things are taught and finally the outcome of the instructional process. So the answer to the question "What teachers do we want to educate" can solely be found in the community of the people that compose each faculty and define through their interactions the institutional modus operandi. Consequently a new framework should be established that spotlights a particular university and its particular people. The framework we propose is based on the following three questions:

-Who teaches at university?

-What is taught at university?

-What do the graduates think about their role as teachers?

Who teaches at university? The answer to this question can easily be found by examining the educational qualifications (e.g. Ph.D, M.A. B.A.) of every faculty member. However, identifying that a person has a Ph.D in a certain discipline is often not enough to define his/her research interests and the paradigm that he/she favours. Qualifications may not provide a holistic picture of the instructor. Moreover, academics often follow different paths after acquiring their educational qualifications. Therefore, in order to have a more comprehensive picture we also need to examine several other issues such as his/her dissertation and the profile of his/her supervisor, especially in the case of neophyte academics. We further need to examine the research projects he/she is involved in along with his/her research output in terms of publications. This investigation will roughly sketch the picture about the 
school of thought favoured by each and every faculty member (e.g. positivism, radical constructivism, critical theory, neo liberalism, eclecticism etc.). This picture needs to be complemented by the impact that each instructor has on the students of the department. Hence, we further need to investigate the number of courses that every faculty member teaches, the number of instructional hours, the percentage of student enrollment and the ECTS allocated to his/her courses.

What is taught at university? Academics may favour one paradigm over another. Their epistemological assumptions and conceptual models are usually reflected in their scientific publications. However, their epistemological profile may, or may not be reflected in their lessons. Often other factors may determine what is taught. For example an instructor may use the syllabus and material produced by other people because it is an easy solution and no extra work is required. The instructor may also choose a specific book for his/her course because it is the only one available. In this case, students will have to study specific material that may not reflect their instructor's epistemological profile. Bearing these in mind, we need to examine the outlines of each lesson and their bibliography.

We also need to examine the instructional methods used in every course, acknowledging that the enacted and the experienced curriculum is much more important than the official-explicit curriculum (Goodlad, 1979). For example the course content may include the notion of collaborative learning. If students are taught about collaborative learning through lectures, they will most likely not be able to apply its principles into their practice (Braund \& Campbell,
2010). Hence, the hidden curriculum, which is incorporated into the modus operandi of the instruction (Jackson, 1968), undermines the realisation of the objectives of the written curriculum. Despite the fact that collaborative learning is officially declared in the content of the lesson, students will unofficially learn that this is something that cannot be applied.

What do the graduates think about their role as teachers? This is the most important question in determining the intended teacher profile. The answers given by the graduates will provide insights about whether there is a cohesive vision about the intended teacher or whether the outcome of the program is based on chance after random exposure to various types of content and instructional methods. Instructors may, or may not, teach according to their epistemological assumptions. Different instructors have different impact upon student learning. So the answer should be based on the graduates ${ }^{\text {ee }}$ personal beliefs and theories about what is teaching and learning: What do they believe about learning, how do they comprehend their role as teacher in the teaching process and how do they feel about the role of the teacher as a social agent (Entwistle et al., 2000; Nespor, 1987; Neophytou et al 2011; Neophytou \& Koutselini, 2008). Despite their inexplicable nature, research demonstrates that beliefs play a pivotal role in how teachers interpret pedagogical knowledge, conceptualize teaching tasks, and subsequently enact their teaching decisions (Bryan, 2003). Consequently, accurate information about the impact that the university has on its graduates will be the 
difference between their beliefs before entering and after graduating from the university. This picture should be further clarified by examining the way these graduates teach.

\section{Conclusion}

Teacher education in previous times in Cyprus could be interpreted by the social factors of the particular era. The state, or other major social stakeholders, controlled teacher-training institutes. Therefore, the variations in the society in terms of aspirations and priorities could provide a framework for illuminating the decisions made in teacher training. However, since the university has undertaken teacher education, things have changed. As a consequence of the privilege of autonomy that university instructors have, the answer about the intended teacher cannot be found outside the university. It cannot even be found in the curriculum of the university, since this is nothing more than a rough outline of general guidelines allowing multiple interpretations. Students are exposed to multiple views and representations orchestrated intentionally or unintentionally, by faculty members.

As long as introspection is encouraged, the graduate may become what Gellner (1996) defines as the "modular man"; a type of individual who is composed of bits and pieces that are agglutinative and can be supplemented but also reshuffled, recombined, replaced and modified as the circumstances may demand (Gellner,1996). Instead of a man who is entirely the product of and absorbed by a particular culture, the modular man "can combine into specificpurpose, ad hoc, limited associations, without binding him/herself. In this context, collective identities and culture-that were used to define the intended teacher profile- are replaced by individualism. However, examining individualism at its extreme end, through a Marxistic standpoint (Blackledge \& Hunt, 1985), we may argue that the autonomous function of the university fosters the creation of a new bourgeoisie, a state within the state, that bases its existence on the separation of the man from himself, as well as from his neighbours, leading to alienation and atomization. The lack of a concise mission statement and a collective vision about the intended teacher profile bears the risk of developing an individual who may lack the ability to connect with other people and pursue a vision worth pursuing. Our era is considered to be the era of democracy and pluralism. However, in the absence of a collective vision, pluralism is transformed into "a cacophony of individual voices" (Pinar, 2011). Individuals may end up serving, no other purpose, than the preservation of their institutional self. In order to avoid this unfortunate event, the question about what teacher we want to have should never be left without an answer. This should be the first question that the community of the faculty members needs to answer.

\section{References}

Blackledge, D.A, \& Hunt , B.A. (1985). Sociological interpretations of education. Worcester: Taylor \& Francis. [Full text] [Back to text] 
Braund, M. \& Campbell, B. (2010). Learning to Teach about Ideas and Evidence in Science: The Student Teacher as Change Agent. Research in Science Education, 40(2), 203-222.

[Full text] [Back to text]

Bryan, L.A. (2003). Nestedness of beliefs: Examining a prospective elementary teacher"s belief system about science teaching and learning. Journal of Research in Science Teaching, 40(9), 835-868.

[Full text] [Back to text]

Eisner, E. \& Vallance, E. (Eds.) (1974). Conflicting conceptions of curriculum. Berkeley:

McCutchan.

[Abstract] [Back to text]

Entwistle, N., Skinner, D., Entwistle, D. and Orr, S. (2000). „Conceptions and Beliefs About "Good Teaching": an integration of contrasting research areas ${ }^{\mathrm{ee}}$. Higher Education Research \& Development, 19(1), 5-26. [Full text] [Back to text]

European Communities (2001). European report on the quality of school education. Sixteen quality indicators. ISBN 92894-0536-8 [Full text] [Back to text]

Fanon, F. (1961). The wretched of the earth. New York: Grove Weidenfeld. [Full text] [Back to text]

Freire, P. (1998). Pedagogy of freedom. New York: Rowman and Littlefield. [Full text] [Back to text]
Gellner, E. A. (1996). Conditions of Liberty: Civil Society and Its Rivals. London: Penguin. [Abstract] [Back to text]

Getzels, J.W., \& \& Guba, E.C., (1957). Social behavior and the administrative process. School Review, 65, 423-41. [Full text] [Back to text]

Goodlad, J. (1979). Curriculum inquiry: The study of curriculum practice. New York: McGraw Hill. [Abstract] [Back to text]

Hill, D. (2006). Six Theses on Class, Global Capital and Resistance by Education and Other Cultural Workers. In: O-P. Moisio and J. Suoranta (Eds.) Education and the Spirit of Time. Rotterdam, Netherlands: Sense Publishers. http://www.sensepublishers.com /books/pdf/90- 77874-17-8.pdf [Full text] [Back to text]

Hoy, W. \& Miskel. C. (2007). Educational Administration: Theory, Research, and Practice ( $7^{\text {th }}$ ed.).New York: McGrawHill. [Abstract] [Back to text]

Jackson, P. (1968). Life in classrooms. New York: Holt, Rinehart \& Winston. [Full text] [Back to text]

Karlsson, J.Ch.(2011). People cannot only open closed systems; they can also close open systems. Journal of Critical Realism, 10 (2), 145-162. [Full text] [Back to text]

Kizilgiourek, N. (1999). Kipros: to adiexodo ton ethnikismon 
[Cyprus: Nationalisms ${ }^{\text {ee }}$ deadend]. Athens: Mavri Lista. [Abstract] [Back to text]

Kliebard, H. (1986). The struggle for the American curriculum 1893-1958. Boston, MA.: Routtledge \& Kegan Paul. [Abstract] [Back to text]

Kokkinoftas, K. (1997). Kykkotika meletimata. [Studies from the Kykkos monastery archives Vol. A]. Nicosia: Poltitistiko Idrima Archangelos[ Archangelos Cultural Foundation]. [Back to text]

Koutselini, M. (1997). I ekpadeftiki politiki aki to mathima ton archiaon ellinikon stin kipro. [Educational Policy and the Lesson of Ancient Greek in Cyprus]. Athens: Gregoris. [Back to text]

Mahoney, J. \& Rueshemeyer, D. (Eds) (2003). Comparative Historical Analysis in the Social Sciences. Cambridge: Cambridge University Press. [Full text] [Back to text]

Mallinson, V. (1980). An Introduction to the Study of Comparative Education ( ${ }^{\text {th }}$ ed.). London: Heinemann. [Abstract] [Back to text]

Maratheftis, M. (1992). To kipriako ekpaideftiko sistima [The Educational System of Cyprus]. Nicosia. [Back to text]

Maratheftis, M. \& Koutelini, M. (2000). I litoutrgia kai ta programmata tis paidagogikis akadimias Kiprou(1959-1993)[The

Operations and Programs of the Pedagogical Academy of Cyprus
(1959-1993)]. Nicosia. [Back to text]

Mavratsas, C. (1997). The Ideological Contest Between Greek-Cypriot nationalism and Cypriotism 19741995: Politics, Social Memory and Identity. Ethnic and Racial Studies, 20(4), 719-726. [Full text] [Back to text]

Neophytou L. \& Koutselini M. (2008). The Influence of Gender, Age and Experience on the Development of Teacher Perspectives. In A. Ross \& P. Cunningham (Eds.), Reflecting on Identities: Research, Practice and Innovation. Proceedings of the 10th European Conference of the Children's Identity and Citizenship in Europe Thematic Network (pp.541-552). London: CiCe. [Back to text]

Neophytou, L. Koutselini, M.,\& Kyriakides, L.(2011). The effect of Teachers ${ }^{\text {ee Personal Beliefs and }}$ Emotional Intelligence on the Quality and Effectiveness of teaching. In A. Lauriala, R., Rajala, Ruokamo, H. \& O., Ylitapio-Mantyla (Eds.). Navigating in Educational Contexts. Identities and cultures in dialogue (pp. 207-227). Rotterdam: Sensei Pubishers. [Full text] [Back to text]

Neophytou,L. (2004). I kliromomia tis apikiokratias stin Kipro[The colonial legacy in the education of Cyprus]. In A. Gagatsis, A., Evangelidou, E. Ftiaka, L. Kyriakides, N. Tsangaridou \& M. Koutsoulis (Eds.). Contemporary 
Trends in Educational Research and Practice. Proceedings of the VIII Conference of the Pedagogical Society of Cyprus (pp.99-112). Nicosia. [Back to text]

Nespor, J. (1987). The Role of Beliefs in the Practice of Teaching. Journal of Curriculum Studies, 19(4), 317-328. [Full text] [Back to text]

Ngugi, W. T.(1981).Writers in Politics: a Re-engagement with Issues of Literature and Society. Oxford: James Currey. [Abstract] [Back to text]

OECD (2007). Education at a Glance. 2007 OECD Indicators. ISBN 92-64- 032886 [Full text] [Back to text]

Papadakis, Y. (2005). Echoes from the Dead Zone: Across the Cyprus Divide. London: I.B.Tauris. [Full text] [Back to text]

Pasiardes, P. (2007). Cyprus. In W. Hörner et al. (Eds.). The Education Systems of Europe (pp.202-222). Dordrecht: Springer. [Full text] [Back to text]

Persianis, P. (1978). Church and State in Cyprus Education. Nicosia. [Back to text]

Persianis, P. (1981). The Political and Economic Factors as the Determinants of Educational Policy in Independent Cyprus (1960-1970). Nicosia: Pedagogical Institute. [Back to text]
Persianis, P. (1992). History of Education in Cyprus. Nicosia: Pedagogical Institute. [Back to text]

Pinar, W. (2011). What is Curriculum Theory.(2nd ed.). N.Y: Routledge. [Full text] [Back to text]

Polyviou, P. (1980). Cyprus Conflict and Negotiation 1960-1980. London: Duckworth. [Back to text]

Rhoads, R.A. \& Torres, C.A. (Eds.) (2006). The university, State, and Market: the Political Economy of Globalization in the Americas. Stanford: Stanford University Press. [Full text] [Back to text]

Schutt, R. K. (2006). Investigating the Social World: The Process and Practice of Research. London: SAGE Publications. [Abstract] [Back to text]

The Pedagogical Academy of Cyprus (1960). Epetiris PAC (19591960), Ar. 1 [PAC Yearbook (1959-1960), No. 1]. Nicosia: The Pedagogical Academy of Cyprus. [Back to text]

The Pedagogical Academy of Cyprus (1970). Epetiris PAC (19691970), Ar.11 [PAC Yearbook (1969-1970), No. 11]. Nicosia: The Pedagogical Academy of Cyprus. [Back to text]

The Pedagogical Academy of Cyprus (1972). Epetiris PAC (19711972), Ar.12 [PAC yearbook, (1971-1972), No. 12]. Nicosia: 
The Pedagogical Academy of Cyprus. [Back to text]

The Pedagogical Academy of Cyprus (1979). Epetiris PAC (1979), Ar. 20 [PAC Yearbook (1979), No. 20].Nicosia: The Pedagogical Academy of Cyprus. [Back to text]

The University of Cyprus (2010). Undergraduate prospectus (2010-11). Nicosia: The Publication Office of the Service for Research and International Relations of the University of Cyprus. [Back to text]

Vallance, E. (1986). A Second Look at Conflicting Conceptions of Curriculum. Theory into practice, Vol. XXV(1), 24-20. [Full text] [Back to text]
Waller, W. (1932). The Sociology of Teaching. New York: Willey. [Full text] [Back to text]

Weir, W. (1952). Education in Cyprus: Some Theories and Practices in Education in the Island of Cyprus since 1879. Nicosia. Cited in M. Maratheftis \& M. Koutselini (2000). I litoutrgia kai ta programmata tis paidagogikis akadimias Kiprou (1959-1993) [The Operations and Programs of the Pedagogical Academy of Cyprus (19591993)]. Nicosia. [Back to text]

Zeichner, K. \& Liston, D. (1990). Traditions of Reform in U.S. Teacher Education. Journal of Teacher Education, 41(2), 3-20. [Full text] [Back to text] 